\title{
International Congress of the German Mycological Society, University Hamburg, Sept. 16th-23th 2010
}

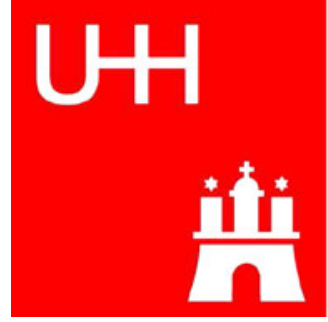

(C) German Mycological Society and Springer 2010

The Congress is split into a field-trip section and a scientific section with lectures. Both sections are bookable separately.

The German Mycological Society invites presentations in the field of mycology or lichenology (talk 10-20 min plus 5 min discussion) as well as posters. Language: English or German. Abstracts: English and German if possible.

Notice of intention to attend the Congress will be June 1 st 2010 at the latest. Late registrations will be charged an additional fee!

\section{Organising Commitee}

Dr. Tassilo Feuerer

Dr. Jürgen Hechler

AK Pilzkunde im Botanischen

Verein Hamburg

Address:

University Hamburg

Biozentrum Klein Flottbek

Ohnhorststr. 18

D-22609 Hamburg

Tel. ++49 (0)40 42816-221

e-mail: feuerer@botanik.uni-hamburg.de

For further information concerning the congress, notice of intention, field-trips and download of registration forms see: http://dgfm-ev.de

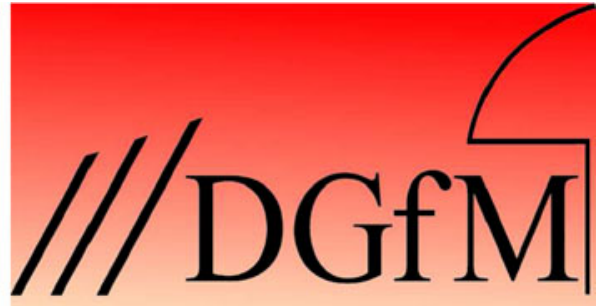

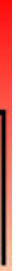

